\title{
Sinus bradycardia treated by long-term atrial pacing
}

\author{
Malcolm Clarke, David W. Evans, and B. B. Milstein \\ From the Regional Cardiac Unit, Papworth Hospital, Cambridge
}

A technique for long-term atrial pacing is described. It uses the system whereby power from an external pulse-generator (including battery) is transferred through the intact skin by inductivecoupling. Once installed, there is no requirement for further surgery to effect battery changes, and the patient can control his heart rate over a wide range to suit his needs.

It is suggested that pacing by such means may offer a preferable alternative to drug therapy in the treatment of low cardiac output due to pathological sinus bradycardia. Two patients successfully treated in this way are reported.

Sinus bradycardia may be a more common cause of disability than hitherto recognized (Shaw and Eraut, 1970). When pathological it is incapacitating because of the limitation it imposes on the cardiac output response to exercise and other stimuli; in very severe cases there may also be a liability to Adams-Stokes attacks. Where indicated, treatment has usually been by sympathomimetic or parasympatholytic drugs (Bellet, 1963; Friedberg, I966), but artificial pacemaking has occasionally been required (Shaw and Eraut, 1970). In these cases the pacing stimuli have been applied to the right ventricle, with consequent loss of the atrial transport function and potential risk of pacemaker-induced ventricular tachydysrhythmia. We here describe an atrial pacing system which is free of these disadvantages and of the great drawback of most 'permanent' pacing systems in current use, namely the requirement for periodic operations to replace the unit. Our early experience suggests that long-term atrial pacing by this technique may be preferable to drug therapy where the latter produces unpleasant side-effects.

\section{Equipment and technique}

The Lucas inductive-coupling system (Abrams, Hudson, and Lightwood, 1960; Taylor, 1966; Clarke, Evans, and Milstein, 1970) has been modified by the makers to provide braided stainless steel ring terminals to the output leads of the secondary coil (Fig. I). The atrium is approached by a small anterior transverse incision and the third right costal cartilage is resected. The pleura is reflected laterally without opening it, and the pericardium over the right atrial appendage exReceived 24 December 1969. posed. A $4 \mathrm{~cm}$. vertical incision is made in the pericardium. The terminals are sutured to the epicardial surface of the right atrium about $2 \mathrm{~cm}$. in front of the sino-atrial node, and a similar distance apart. Additional anchorage and haemostasis are provided by a covering patch of Teflon felt. The pericardium is loosely closed about the leads with 3 or 4 sutures, and the silicone-rubber covered secondary coil left in a subcutaneous pocket at the usual site (Fig. 2). The wound is closed after ascertaining that an adequate pacing stimulus can be induced with the primary coil $4 \mathrm{~cm}$. or more vertically above the secondary.

The external components of the system are standard, the pulse-generator being powered by the universally-obtainable U2 cell. Rate control is in the hands of the patient and a choice of power settings is available. At normal power setting and average rates, the battery life is usually 3 to 4 weeks and changes are quickly, easily, and safely effected by substituting the spare generator with attached primary coil. It is necessary to tape this coil to the skin in the desired position relative to the secondary coil; this is aesthetically unsatisfactory but in practice no great disadvantage.

\section{Case reports}

Case I A 62-year-old man was admitted to this unit in February 1969. He had been dyspnoeic on moderate exertion for 5 years. Sinus bradycardia had been diagnosed and treated with longacting isoprenaline. This produced no sustained improvement and he had to give up his work as a postman. Latterly he had been dyspnoeic on walking a few yards on the flat. He had been orthopnoeic and liable to attacks of paroxysmal nocturnal dyspnoea in spite of the use of five pillows and treatment with diuretics.

He also suffered from Menière's syndrome but gave no history of syncopal attacks.

Physical examination confirmed orthopnoea 


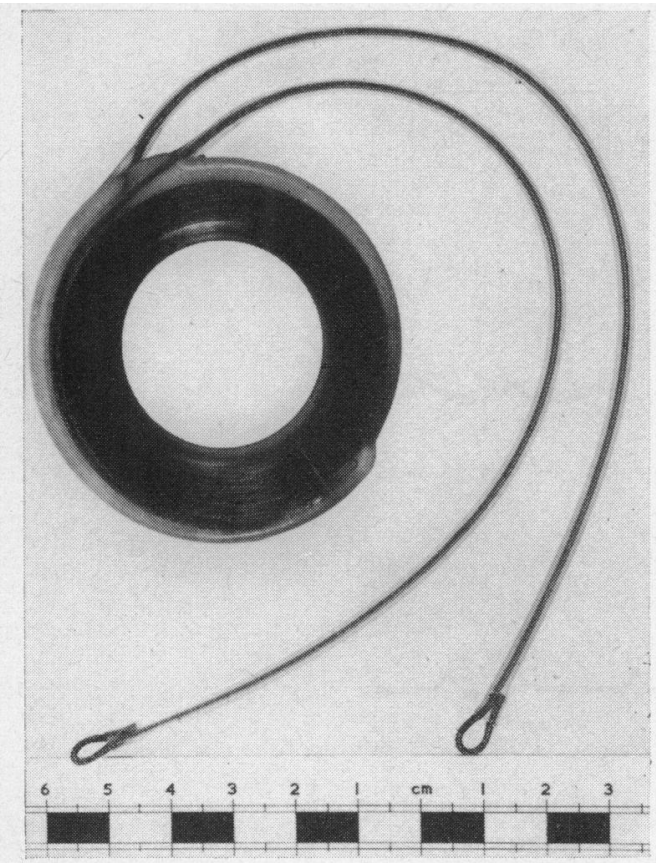

FI I. I Secondary coil and terminals.

with minimal ankle oedema but no gross cardiomegaly or auscultatory abnormality. Right brachial blood pressure was $210 / 85 \mathrm{~mm}$. $\mathrm{Hg}$ and heart rate 35-40 a minute; this rate was not increased by exercise. Chest $x$-ray showed some cardiac enlargement with unfolding of the aorta. The lung fields were clear. The electrocardiogram (Fig. 3) confirmed sinus bradycardia and revealed occasional nodal escape; it was otherwise normal. No other evidence of intrinsic cardiac disease was found.

Intravenous atropine (0.6-r.2 mg.) resulted in heart rates up to 60 a minute but oral parasympatholytics produced only unpleasant general effects without useful cardiac acceleration. Temporary transvenous right ventricular pacing was instituted as a therapeutic test. At pace-made rates of 70-80 a minute he lost his orthopnoea and was able to walk indefinitely on the flat and climb 2 flights of stairs without distress.

The temporary system was removed and a permanent inductive-coupling atrial system inserted, as described above. Atrial fibrillation ensued on the first post-operative day and persisted, with rapid ventricular response, until spontaneous reversion to sinus rhythm on the sixth day. During this time, when the pacemaker was turned off and digitalization started, he felt particularly well. Resumption of slow sinus rhythm was accompanied by deterioration of mood and return of his dyspnoea. Atrial pacing at 70-80 a minute was therefore reinstituted and he again became very bright and cheerful and free of dyspnoea. He has remained well and active since discharge from hospital ro months ago. His right brachial blood pressure is now about $140 / 70 \mathrm{~mm}$. Hg. The pulse-

FIG. 2 X-ray of chest showing internal components in position.

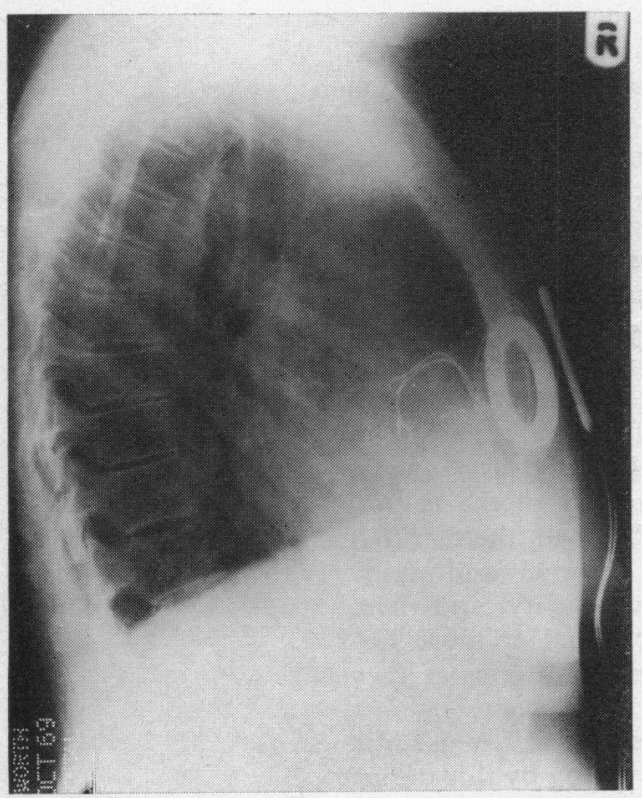

FIG. 3 Upper tracing: pre-operative electrocardiogram of Case I. Lower tracing: postoperative electrocardiogram of Case I. The pacing signals (one of which is arrowed) have been emphasized during reproduction.
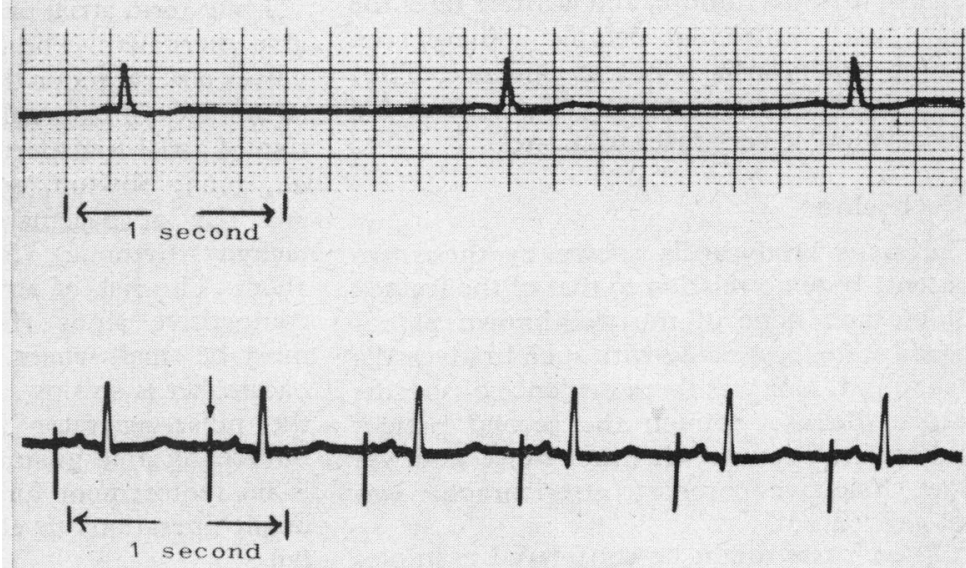
generator has been used in the 'high-power' mode in this case since the late post-operative period.

Case 2 A 53-year-old woman was admitted to the unit in April 1969. Her symptoms of dyspnoea and dizziness on slight exertion, effort angina, and undue fatiguability extended over a period of 9 years. They had forced her to retire from her nursing post.

Clinical examination revealed no abnormality apart from a fixed heart rate of 40 a minute, with occasional irregularity, and right brachial blood pressure of $130 / 85 \mathrm{~mm}$. $\mathrm{Hg}$. The chest $x$-ray was normal.

The electrocardiogram showed sinus bradycardia occasionally interrupted by ventricular extrasystoles. Other investigations yielded no relevant findings.

Test infusions of isoprenaline and atropine both produced a satisfactory increase in heart rate, but she found the side-effects of the oral preparations intolerable. A permanent atrial pacing system was installed and was functioning normally (on 'lowpower' setting and usually about 70 a minute) at follow-up 7 months later. She had experienced no effort dyspnoea or dizziness and no angina since the operation; she volunteered the information that she could not remember ever having felt so alert before.

\section{Pace-made electrocardiogram}

Fig. 3 shows the sequence of atrial stimulation by the pacemaker and ventricular activation after an appropriate PR interval in each case. As noted by Lister et al. (1965), this interval varies directly with heart rate (Fig. 4) and not inversely as in the physiological state or when heart rate is increased by atropine or isoprenaline. In Case I the PR interval increased from $0.14 \mathrm{sec}$. at a frequency of 40 a minute to 0.24 sec. at 100 a minute. In Case 2 the interval was $0.18 \mathrm{sec}$. at 60 a minute and $0.24 \mathrm{sec}$. at I35 a minute. Both patients have physiological PR intervals at their usual pace-made rates of 70-80 a minute, and at these rates the nodal and ventricular ectopic activity seen during bradycardia is not in evidence. They have not been tested for development of AV dissociation at very fast atrial rates.

\section{Discussion}

The sinus bradycardia shown by these two patients bore no relation to that of the trained athlete and none of the well-known pathological states associated with such bradycardia was found. Nor was there evidence of specific cardiac disease, though the second patient had angina pectoris when her pulse rate was slow. Selective coronary arteriography was not carried out.

These cases might be considered examples of the 'lazy sinus syndrome' (Shaw and Eraut, 1970), a disease state that may prove

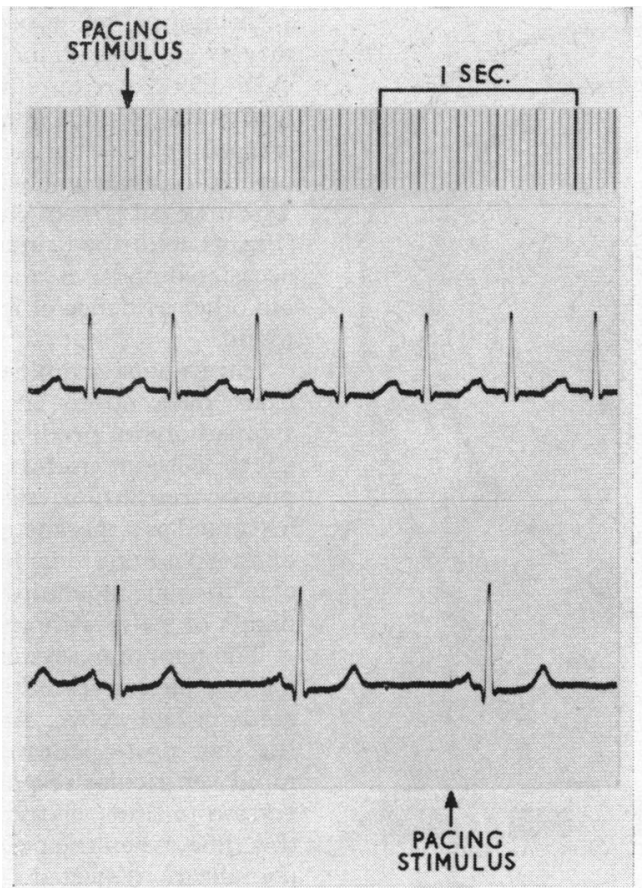

FIG. 4 Pace-made electrocardiogram (Case 2) showing variation of $P R$ interval with heart rate. Upper tracing: pacemaker rate 135 a minute, $P R=0.24 \mathrm{sec}$. Lower tracing: pacemaker rate 60 a minute, $P R=0 \cdot 18 \mathrm{sec}$.

to be not rare. Drug treatment of this condition is frequently unsatisfactory because of inadequate rate response or because of intolerable side-effects inseparable from the drug's action. Chief of these are mouth dryness and accommodation disturbance in the case of atropine and like preparations, and tremulousness and a most unpleasant feeling of tension with isoprenaline.

Long-term atrial pacing provides a practicable alternative. The technique described involves a very minor thoracotomy but has the advantages of external rate control, preservation of atrial transport function (Johansson $e t$ al., 1963; Sowton, 1965), and avoidance of any risk of pacemaker-induced ventricular tachydysrhythmia (Siddons and Sowton, 1967). The risk of atrial dysrhythmia due to competitive sinus rhythm (Sowton, 1965) must be small where the rate of the natural pacemaker is so slow. Above all, the fact that the pulse-generator is external and easily interchangeable guarantees safety, and there is no requirement for biennial or more frequent operations to change batteries as they fail.

Thoracotomy could be avoided by use of a transvenous system, but pacing by this means 
has proved unreliable because of instability of the electrode tip (Kastor et al. 1969). Stable transvenous atrial pacing has been accomplished by placement of the electrode in the proximal portion of the coronary sinus, but this method is not recommended for routine use because of the potential hazards of perforation and thrombus formation (Moss, Rivers, and Cooper, 1969). It is concluded that, at present, the most reliable way to establish long-term atrial pacing is to suture the electrodes to the atrium.

We wish to thank Dr. J. H. N. Bett of Melbourne, Australia, for his part in suggesting this method of treatment. We are grateful also to the staff at Joseph Lucas' Research Laboratory for their interest and prompt assistance, to Dr. H. A. Fleming for permission to report Case 2, and to the Photographic Department at Addenbrooke's Hospital, Cambridge, for reproductions of the figures.

\section{References}

Abrams, L. D., Hudson, W. A., and Lightwood, R. (I960). A surgical approach to the management of heart-block using an inductive coupled artificial cardiac pacemaker. Lancet, I, 1372.
Bellet, S. (1963). Clinical Disorders of the Heart Beat, 2nd ed., p. II8. Henry Kimpton, London.

Clarke, M., Evans, D. W., and Milstein, B. B. (1970). Long-term pacing with an inductively coupled system. In preparation.

Friedberg, C. K. (1966). Diseases of the Heart, 3rd ed., p. 486. W. B. Saunders, Philadelphia and London.

Johansson, B. W., Karnell, J., Malm, A., Sievers, J., and Swedberg, J. (1963). Electrocardiographic studies on patients with an artificial pacemaker. British Heart fournal, 25, 514.

Kastor, J. A., DeSanctis, R. W., Leinbach, R. C., Harthorne, J. W., and Wolfson, I. N. (1969). Long-term pervenous atrial pacing. Circulation, 40, 535 .

Lister, J. W., Stein, E., Kosowsky, B. D., Lau, S. H., and Damato, A. N. (1965). Atrioventricular conduction in man. Effect of rate, exercise, isoproterenol and atropine on the P-R interval. American fournal of Cardiology, 16, 516.

Moss, A. J., Rivers, R. J., and Cooper, M. (I969). Long-term pervenous atrial pacing from the proximal portion of the coronary vein. Fournal of the American Medical Association, 209, 543.

Shaw, D. B., and Eraut, D. C. (1970). Sinus bradycardia, sino-atrial block, and lazy sinus syndrome. In Proceedings of the British Cardiac Society. British Heart fournal, 32, 557.

Siddons, H., and Sowton, E. (1967). Cardiac Pacemakers, p. I13. Charles C. Thomas, Springfield, Illinois.

Sowton, E. (1965). Artificial pacemaking and sinus rhythm. British Heart fournal, 27, $3 \mathrm{rr}$.

Taylor, A. B. (1966). Experience with cardiac pacemaking. British Medical fournal, 2, 543. 